\title{
A Web-Based Instructional Module for Research and Learning in Design and Analysis of Enterprise Systems
}

CHARU CHANDRA

Department of Industrial and Manufacturing Systems

Engineering

University of Michigan - Dearborn

\section{SAMEER KUMAR}

Department of Manufacturing Systems and Engineering

University of St. Thomas

\section{AbSTRACT}

This paper describes an instructional module designed to create a repository for introducing students and industry practitioners to enterprise systems. A web-based design was used to make the module scalable, utilizing Internet capabilities and adapting a systemic approach to disseminate information on research projects. Important characteristics of a web site for organizing information are described. A generic web design problem is outlined and a case study on supply chain management is illustrated. Uses of the module on curricula that satisfy cognitive goals of enterprise system education are discussed. The module offers extensibility to incorporate live applications through the web site.

\section{ENTERPRISE SYSTEMS: EVOLUTION and Pedagogical Issues}

In the current environment of globalization, strategic alliances among organizations are steadily growing. A collaborative environment promoting cooperation among enterprise partners is required in order to meet their individual and collective goals. An enterprise system is designed to meet these needs. It integrates parts such as, functions, departments, and divisions of an enterprise into a whole with shared objectives, technology, operations, processes, constraints, resources, and knowledge. ${ }^{1}$ This network of autonomous members, when designed to coordinate demand with supply, is a supply-chain.

This paper describes an instructional module for research and learning in design and analysis on enterprise integration and supply chain management topics.* The purpose of the module is twofold:

\footnotetext{
*The web site http://www.engin.umd.umich.edu/ charu/Res_Index.html offers an overview of an approach to enterprise integration framework, applied on the Enterprise Modeling and Analysis task of the Demand Activated Manufacturing Architecture project sponsored by American Textile industry. It showcases collaborative research between Los Alamos National Laboratory, a unit of the University of California; and the University of Michigan.
}

1) to share knowledge gained by authors through this research with peers in research and academe, and 2) to create a learning repository for introducing students and practitioners to enterprise systems, in particular, the design and analysis issues in a supply chain. A webbased design was used to make the module scalable and utilize Internet capabilities.

The paper is organized as follows. The enterprise system design and analysis process is defined. Cognitive goals of research and learning module to support this process are outlined. A webbased design is presented. Features of module with the proposed framework applied to a supply chain management problem are presented. Implications of module on engineering education are discussed.

\section{ENTERPRISE SYSTEM DESIGN AND ANALYSIS PROCESS}

Several factors contribute to increasing interest in integrated enterprise systems. First, it is realized that management of interrelated systems leads to improvement in enterprise productivity. Second, advances in information technologies complemented by sophisticated decision support systems enable delivery of these systems. The motive for pursuing research on supply chain, a class of enterprise system, is proposing a framework that deals with these issues effectively. This approach to enterprise integration proposes domain-independent problem solving and modeling to develop common information and process flow architectures of an enterprise, and domain-dependent analysis and implementation. The purpose is to ascertain characteristics of the problem independent of its environment. Analysis methods help to understand characteristics of the solution methodology as well as provide specific guarantees of effectiveness. Invariably, insights gained from analyses can be used to develop effective problem solving tools and techniques. The focus of this paper is to emphasize, how research and learning issues in design and analysis of enterprise systems may be used to support pedagogy in engineering education. For this purpose, a web-based module for supply chain management has been developed.

\section{COGNITIVE GoALS}

The primary objective of this module is helping students engaged in research and practice of enterprise systems to develop an understanding of structure, control, and interactions among its components for design and analysis of problem solutions. Based on this objective, cognitive goals were established to create increased awareness in three categories: 
1. Systems thinking about enterprise concepts.

2. Perception about problem solving, from the traditional "island of problem-solving" to an integrated enterprise view.

3. Learning by practicing enterprise integration problem-solving skills on applications.

The first goal is met by emphasizing systems concepts-framework, theory, model, hypothesis, problem-solving technique, entity, relationships, structure, control, and their integration in developing solution methodologies.

The second goal is addressed by emphasizing model development based upon primary characteristics - structure, representation, diagnosis, and prescription. Models for first two characteristics are designed, independent of system's application domains. For the remaining two characteristics, models are designed dependent on problem domain. Thus, this approach effectively differentiates between structural and diagnostic issues in offering flexible enterprise system problem-solving methodological designs.

The third goal is to enable students to integrate theoretical knowledge into practice. This is achieved by mapping abstract system concepts into simulated models of an enterprise with software tools and studying their behavioral traits under different scenarios.

\section{IV.USER INTERFACE DESIGN}

In order to develop an instructional module that satisfies above cognitive goals, it is essential to create an effective user interface design. Three main considerations that guided the user interface for web design capabilities are discussed below.

\section{A. User Friendliness}

Primary characteristics of user friendliness in a web site are audience, content, and usability. It is essential to determine audience of the web site so that relevant information can be offered. ${ }^{2-4}$ Research audiences for this web site have interest in design, modeling, and analysis of supply chain. Practitioner audiences are interested in applications of enterprise integration and supply chain concepts in various domains.

Content of the web site is strongly linked with audiences' information needs and its presentation. ${ }^{2}$ The way to increase value of the web site to users is to enhance the quality of its content. ${ }^{5}$ For instance, integration is explained as a mechanism with roots in control theory, organizational strategies, and planning and allocation of resources in operations research. For practitioners, topics relate to enterprise integration and supply chain management applied to problem domains such as, in forecasting, and inventory management.

The usability of the web site is to enable audience obtain specific information from it. The construction of the web site offers utility to its primary user, a researcher in enterprise integration and supply chain. It is designed to navigate important focus areas and drilling down for details on these topics.

For a web-design to provide an effective user interface, its architecture must incorporate these web characteristics. This can be achieved best with a modular web design.

\section{B. Modularity}

Assimilation and dissemination are main components of a modular web design.
Assimilation relates to identifying, locating, and selecting information pertinent to the web site.

1. Identifying published literature in supply chain and related areas appearing in, (a) books and articles, (b) web pages maintained by peers in academe, and industry.

2. Locating supply chain topics via search in research indexes.

3. Selecting information relevant to the focus of research. That is, pruning information for common interface to managing a supply chain system, systems theory, systems engineering, and production planning and control areas.

Problems associated with assimilation of information relate to validity, currency, and reliability of sources. This is verified by ensuring that information captured:

1. relates to modeling, and analysis issues of supply chain valid only to the problem focus

2. is current in terms of its publication date or significance of the problem

3. can be relied upon based on its citation record and applicability to problems.

The dissemination process involves creating a database and a web site for its use. Its main activities are:

- organizing information in supply chain management in a database using clusters of related topics

- accessing information for topics through structured menus and formatted pages

- providing connections for links between information across networks.

Due to massive information that is placed on the web, investigating layouts, connecting methods and software tools enable developing improved techniques for this activity.

Web Site Design. A strategy for design of the web site helps in focusing information presented towards its target audience. A design also facilitates adopting appropriate model(s) for retrieving information needs, identified in the web-design problem. Scenarios varying in user profile suggest differing opportunities for interactivity and information manipulation in Web site design. ${ }^{6}$ Table 1 compares three such approaches.

A mixed web design approach has been applied to the case study described here. A large spectrum of web audience can be accommodated with this type of design through development of varied learning environments to suit their interests and needs.

A web application development strategy is needed to deal with dissemination of information. A software tool kit is required for implementation of the web-site.

\section{Technical Feasibility}

A Web Application Software Development Strategy. The output for this case study is shown on one or many formats, such as document, presentation, working model, and application. A combination of techniques that allowed capturing an array of presentation formats was applied namely, frames for pictures and snapshots, “.pdf” files for documents, and hyperlinks for linking application model(s). Frames technique used in organizing information on the web site divides it into a number of sections linked with one another. Representing information on the web site required transferring files while maintaining their original formats. Document saved as ".pdf" files were attached as links to the web site. Finally, disseminating information required that a user request be connected to the database in the web 


\begin{tabular}{|l|l|l|l|l|l|}
\hline $\begin{array}{l}\text { Key Attributes } \rightarrow \\
\text { Design Approach } \\
\downarrow\end{array}$ & Focus & Audience & Information Content & Purpose & Web Tools \\
\hline Business Centered & Selling & $\begin{array}{l}\text { Customers, } \\
\text { Professional } \\
\text { Colleagues }\end{array}$ & $\begin{array}{l}\text { Advertisements, selections, and } \\
\text { comparisons with similar Web Sites. } \\
\text { Tailored for Internet. Source of } \\
\text { information: public domain. }\end{array}$ & $\begin{array}{l}\text { To sell ideas or } \\
\text { products. }\end{array}$ & $\begin{array}{l}\text { Search Engines } \\
\text { (external), Cookies } \\
\text { (individualization to } \\
\text { Web Site). }\end{array}$ \\
\hline User Centered & Learning & $\begin{array}{l}\text { Students, } \\
\text { Researchers, } \\
\text { Academics }\end{array}$ & $\begin{array}{l}\text { Learning Modules, Research Articles, and } \\
\text { Links to similar Web Sites. Source of } \\
\text { Information: private domain. Tailored for } \\
\text { Intranet. }\end{array}$ & $\begin{array}{l}\text { To present } \\
\text { information in a } \\
\text { focused manner. } \\
\text { Facilitate learning. }\end{array}$ & $\begin{array}{l}\text { Search Engine } \\
\text { (internal), } \\
\text { Presentation tools } \\
\text { (“.pdf" files, etc). }\end{array}$ \\
\hline Mixed & $\begin{array}{l}\text { Selling } \\
\&\end{array}$ & $\begin{array}{l}\text { Colleagues, } \\
\text { Students, } \\
\text { Lustomers }\end{array}$ & $\begin{array}{l}\text { Selections of ideas, Links to Restricted } \\
\text { Web Sites, Research Articles. Source of } \\
\text { Information: public and/or private } \\
\text { domains. Tailored for Internet/Extranet. }\end{array}$ & $\begin{array}{l}\text { To solicit ideas } \\
\text { and to provide a } \\
\text { learning tool. }\end{array}$ & $\begin{array}{l}\text { Search Engines } \\
\text { (external, internal), } \\
\text { Presentation tools } \\
\text { (“.pdf" files, etc). }\end{array}$ \\
\hline
\end{tabular}

Table 1. A comparison of web-design approach.

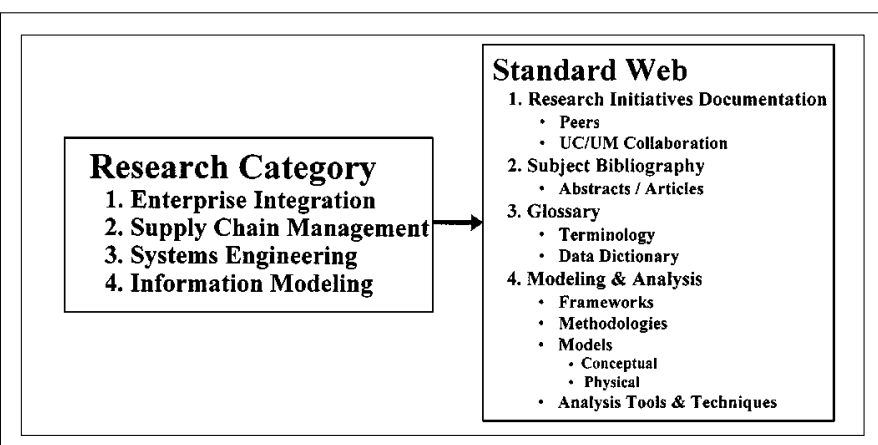

Figure 1. Ageneric template for web development.

site. Core design consideration of any hypermedia system is how it models relationships as links.?

A Web Development Tool Kit. To create a user-friendly web-site, appropriate development tool(s) must be selected. ${ }^{8}$ Key features in web development application tools used for creating the web site are presentation, linkage, visualization, referential, modeling, and process mapping.

\section{FEATURES OF THE WEb-BASED ENVIRONMENT}

In order to illustrate use of the web site, a representative research and learning model has been developed. Its purpose is to demonstrate how research and learning awareness can be enhanced in enterprise integration areas. A standard template depicted in Figure 1 has been used for illustrations. Its components are described below.

The Research Category component of the template describes the focus of research and its categorization. Research in these categories pertains to issues of generic enterprise integration. For each category, information is organized and disseminated in four functional units. For illustrative purposes, these are described for the Supply Chain Management Research category. The Research Initiatives Documentation component benchmarks, research described in this case study with published research. This component has two sections:

1. Peers. Research pertaining to this case study is compared and contrasted with published literature as well as current research at other peer institutions.

2. UC/UM Collaboration. ${ }^{*}$ Collaborative research initiatives between University of California and University of Michigan on topics of mutual interest in the Enterprise Integration and
Supply Chain Management area are described. Figure 2 depicts its web site.

The Subject Bibliography section offers bibliographies on current research topics in the Supply Chain Management area. Brief abstracts, and full text articles are offered.

The Glossary offers a listing of terms and their definitions relative to each research category. A data dictionary of all attributes pertaining to various logical models utilizing object-oriented methodology is provided.

The Modeling and Analysis activity facilitates design and implementation of Supply Chain Management systems. Its components are as follows:

- Frameworks provide a unified roadmap for design and implementation of Supply Chain Management systems with theory, hypothesis, and methodology. ${ }^{9}$

- Methodologies are methods utilized for supply chain problem solving. Through a systematic evaluation process an "As-Is" system is decomposed and analyzed to obtain a "To-Be" model. Figure 3 depicts the proposed seven-step enterprise modeling and analysis methodology. ${ }^{10}$

- Models. A conceptual model of the "As-Is" system is developed using IDEF model representation."* It is elaborated further into a logical model using object-oriented modeling constructs defined by a Unified Modeling Language, and finally a simulation prototype is developed using a simulation language. Figure 4 is an IDEF model representation of an "As-Is" system for production planning function for a textile manufacturer at level 0 , or business level. This generic model can be drilled down to a more specific model for a given problem. Figure 5, is an object-oriented generic model representation of an "As-Is" system for production planning function for a textile manufacturer. Figure 6, depicts a simulation prototype of a generic material processing activity. Each icon in this figure depicts an input, output, and process required for transforming material from one state to the next.

- Analysis Tools and Techniques. The simulation prototype is analyzed on a variety of tools. For value analysis, methods that differentiate value-added from non-value-added components

*This paper documents results of research by first author supported by grants from the Department of Energy, Los Alamos National Laboratory, including sub-contract \# H1757-0019-2G, 11/9/98 on University of Michigan.

**IDEF (Information Definition) technique representation of a system at various enterprise levels namely, a business, function, process, and activity. 


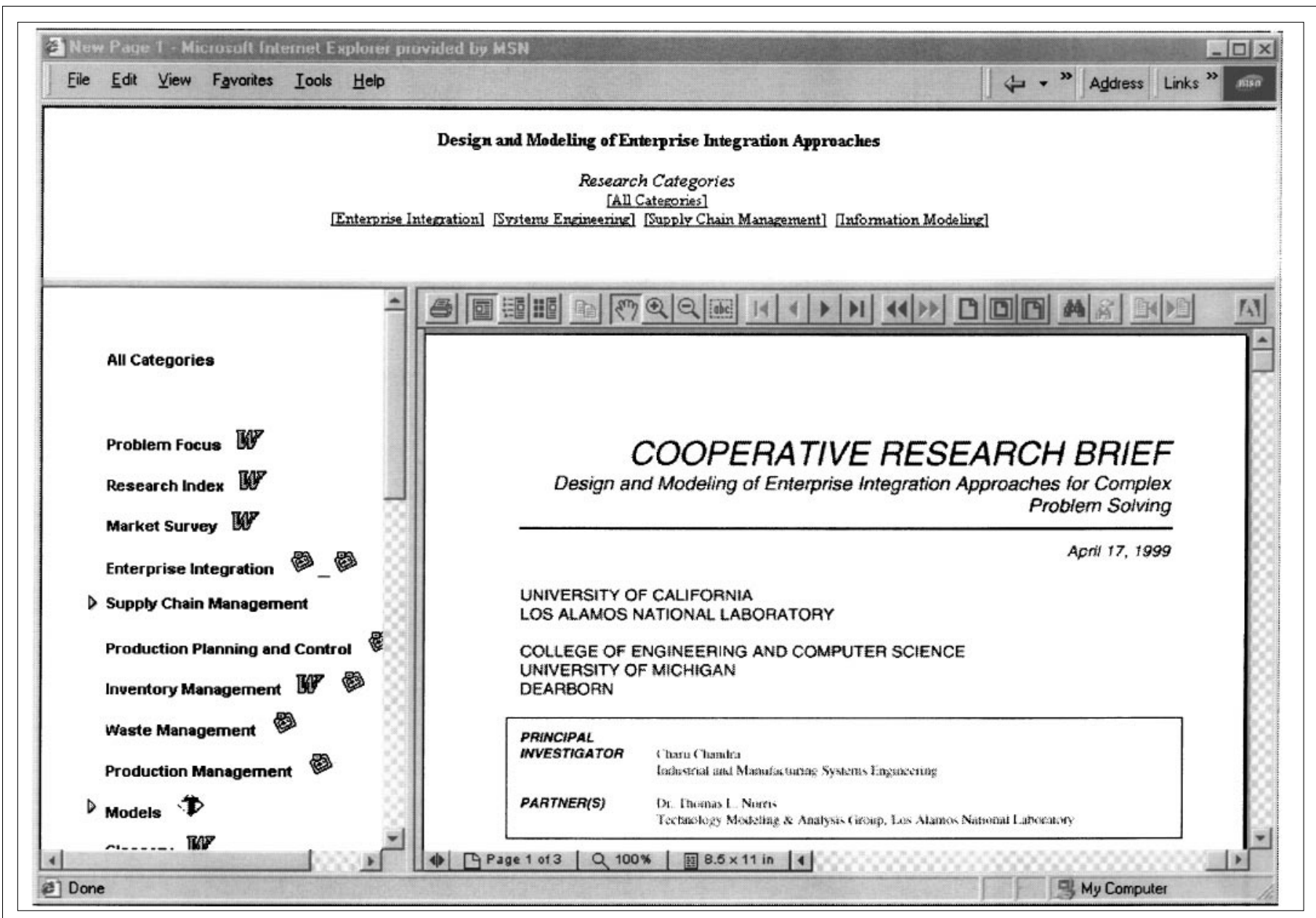

Figure 2. Web site for collaborative research.

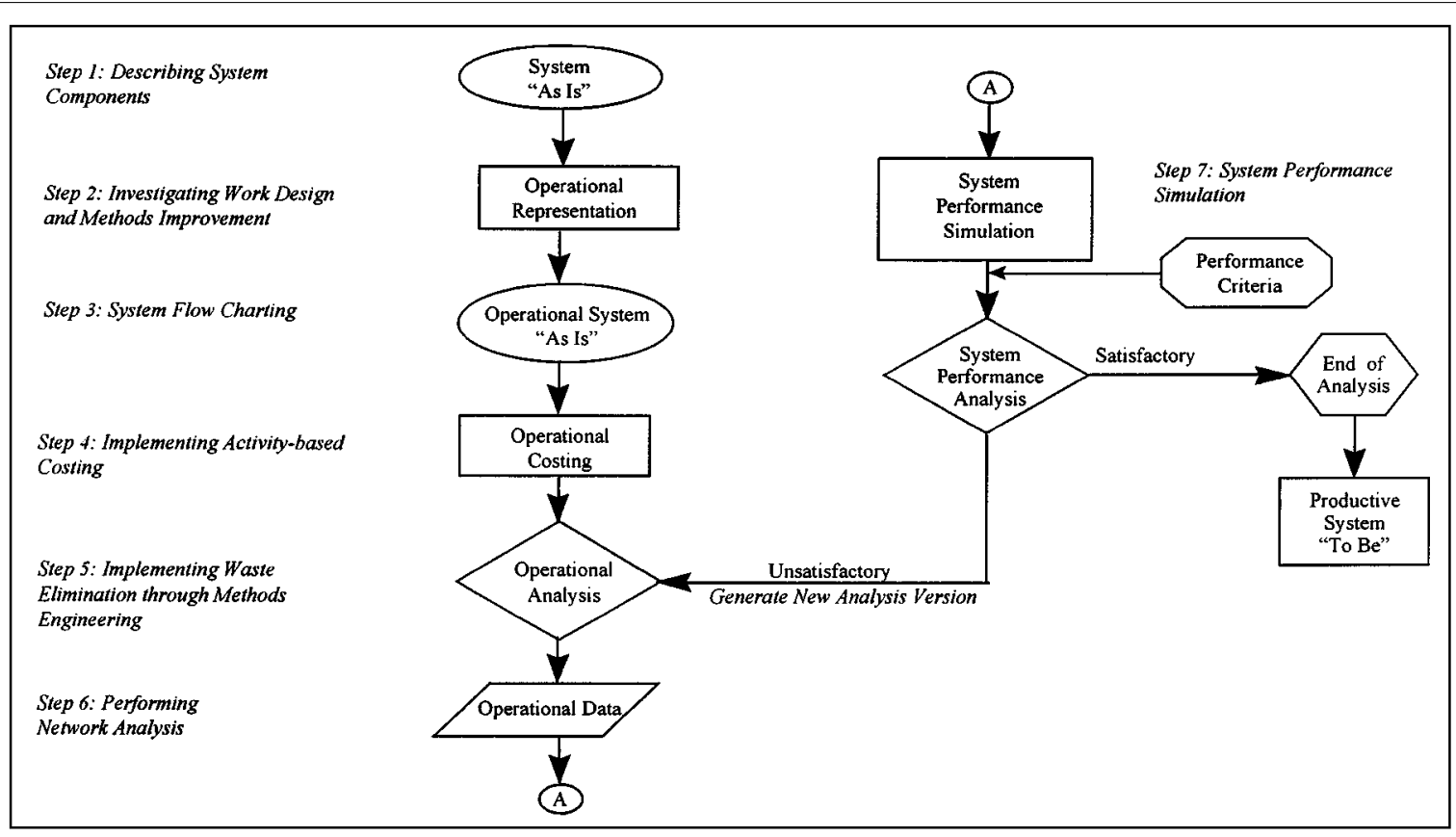

Figure 3. Enterprise system analysis methodology. 


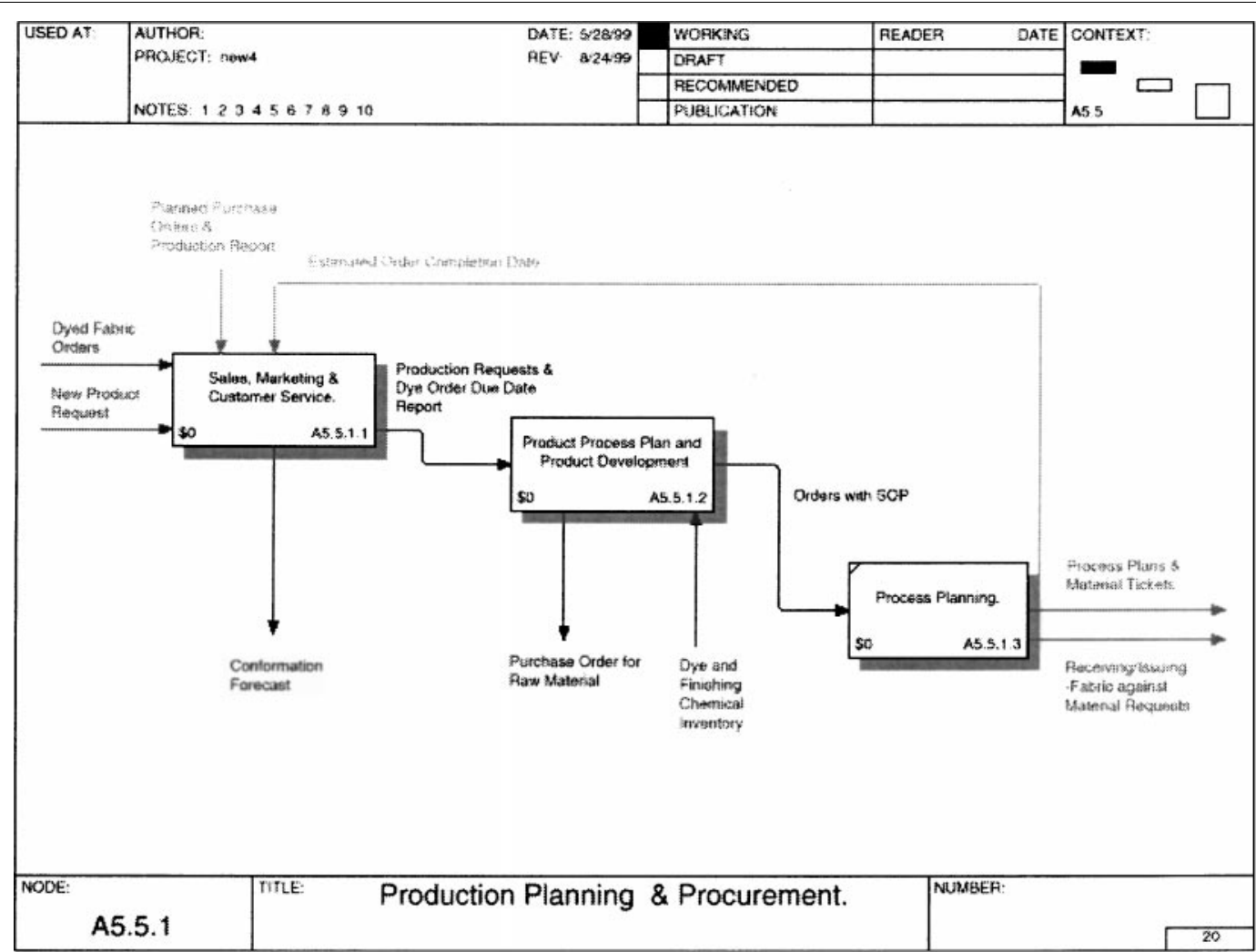

Figure 4. An IDEF-0 model representation of an "As-Is" system for a production planning and procurement function.

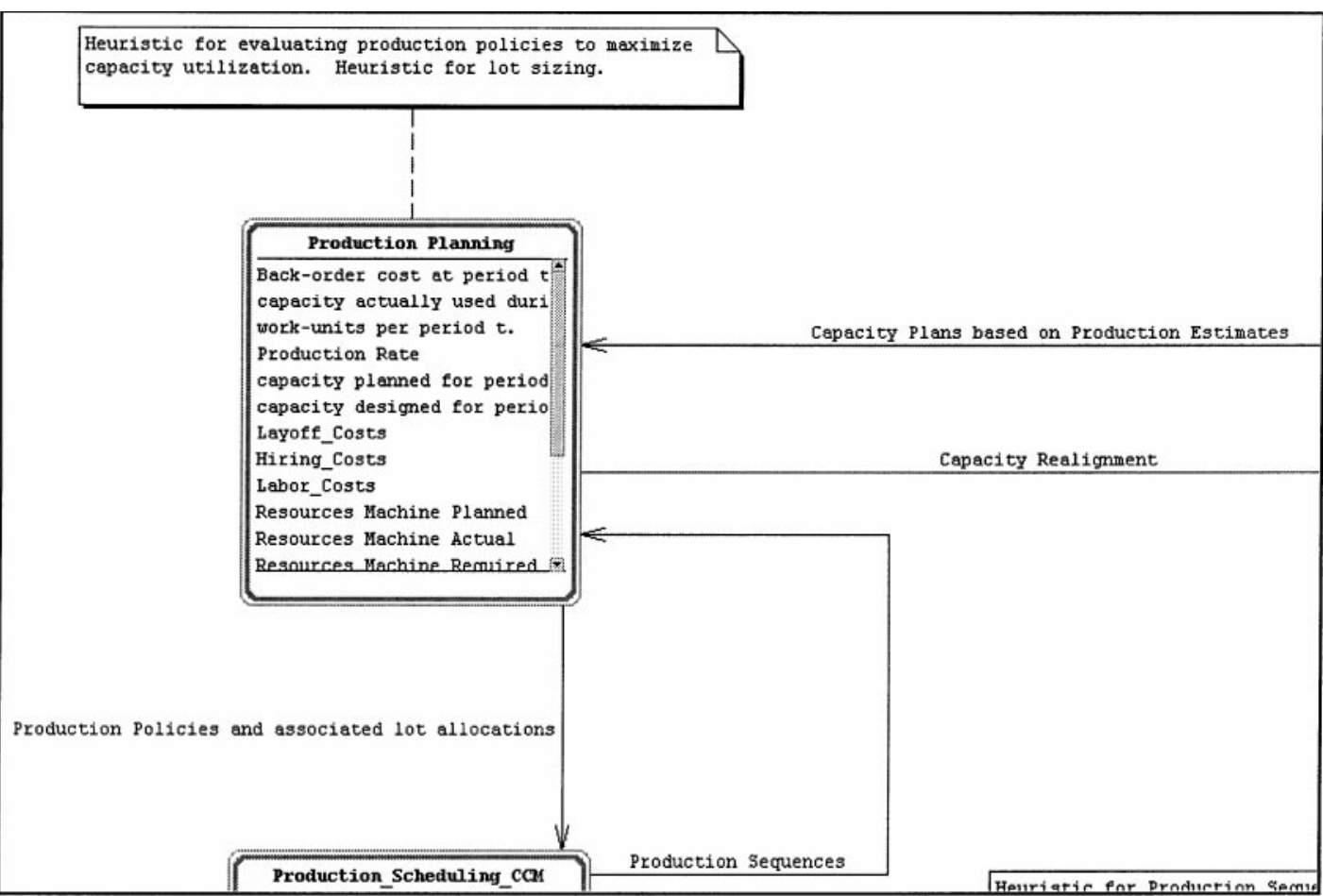

Figure 5. An object-oriented model representation of a production planning function.

of the "As-Is" model are employed. Table 2 differentiates value-added components of a system from its non-valueadded components, offering the decision-maker a basis for improvement. This refined model is subjected to sensitivity analysis utilizing cases that test the validity of the model under various system constraints. The outcome of this analysis process is the "To-Be" model, offering feasible solution(s) for the problem under investigation.

The application of a research and learning module described above highlights, effectiveness of a research web site in promoting 


\begin{tabular}{|c|c|c|c|c|}
\hline \multicolumn{5}{|c|}{ XYZ Summary } \\
\hline Activity & & Current & Proposed & Saving \\
\hline Storage & $\triangle$ & 4 & 0 & 4 to 13 days \\
\hline Set-up & $\underline{I}$ & 3 & 3 & -- \\
\hline WaterialProcessing & 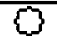 & 3 & 3 & $\ldots$ \\
\hline Inspection & $\square$ & 0 & 0 & --- \\
\hline $\begin{array}{l}\text { Concurrent Processing \& } \\
\text { Inspection }\end{array}$ & 0 & 3 & 3 & $\cdots$ \\
\hline Transport Materials & 6 & 2 & 0 & $x \min$ \\
\hline Delay & 0 & 2 & 2 & -- \\
\hline Handling & $\square$ & 0 & 0 & $\overline{---}$ \\
\hline Packing & $\phi$ & 1 & 1 & --- \\
\hline End Product & F & 0 & 0 & --- \\
\hline Transportation & 8 & 1 & 1 & --- \\
\hline & & & & \\
\hline & & & & \\
\hline \begin{tabular}{|c|} 
Total \\
\end{tabular} & & $\overline{19}$ & $\overline{13}$ & 6 \\
\hline
\end{tabular}

Table 2. Sample result of a generic value analysis of supply chain activities.

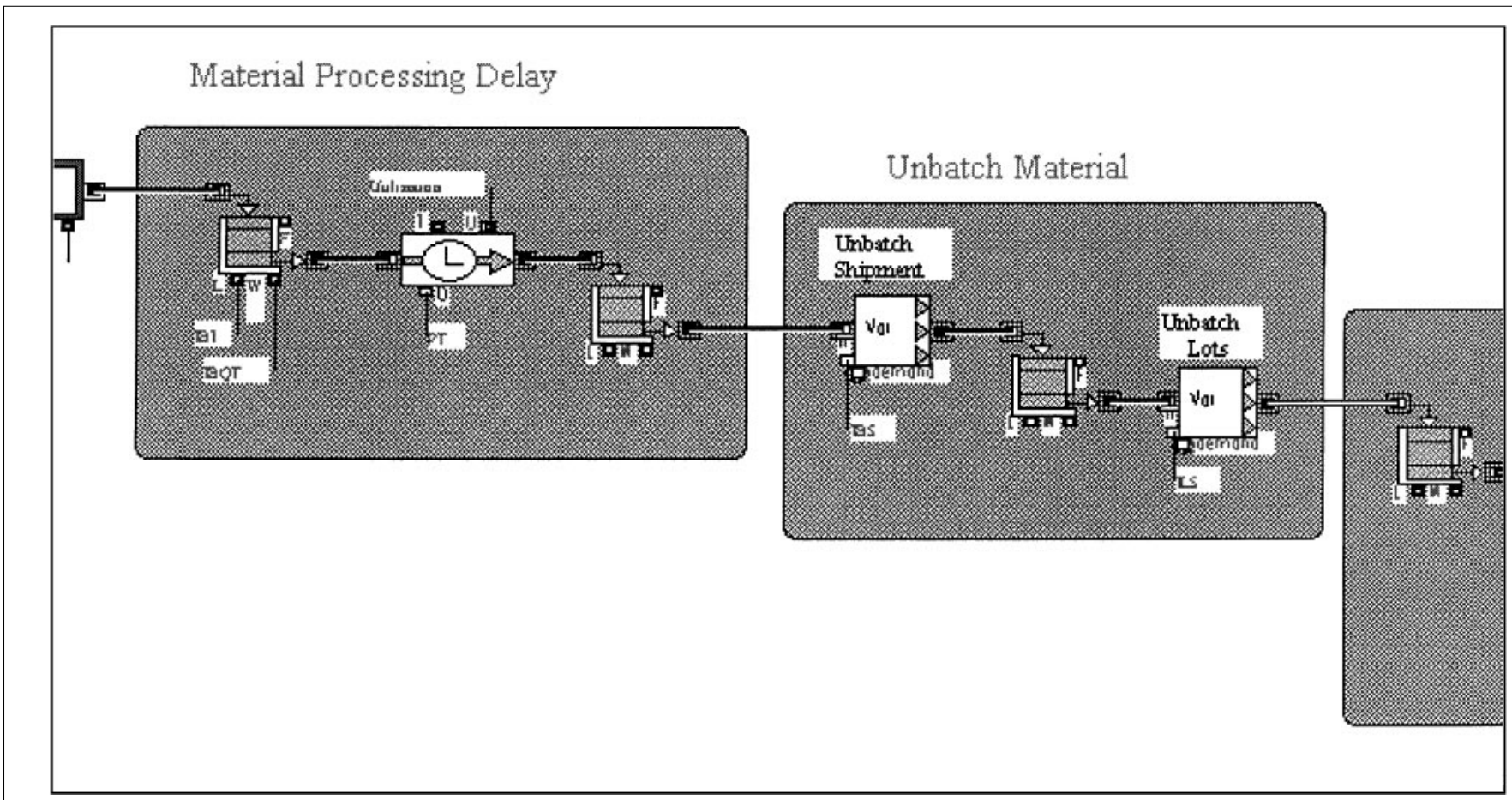

Figure 6. A simulation prototype for a generic material processing activity.

learning of system concepts and their appropriate application in problem solving to specific fields of inquiry.

\section{USING INSTRUCTIONAL MODULE FOR ENGINEERING EDUCATION}

The generic template approach adapted in organizing and disseminating information on the web-site, enables standardization of deliverables for any research and learning categories identified in Figure 1. Curricula for two engineering courses, (a) Supply Chain Management and (b) Enterprise Optimization, similar to those identified in reference 1 , have been structured by the authors around the framework described in the instructional module. Cognitive goals identified in Section III of the paper, were satisfied as follows for these curricula. The theoretical component of these courses emphasizes system thinking, based on relevant theories, hypotheses, methodologies, problem-solving models, and analysis techniques related to supply chain as a class of enterprise systems. Students are instructed in modeling the supply chain using information and process flow techniques to decompose the enterprise at conceptual and logical levels, so that they can develop an integrated view of the problem. This can take the form of modeling the, (a) demand network representing the distribution chain from distributor, dealer and end-consumer, (b) supply network representing tier I, tier II, and raw materials vendors, and (c) integration of 
demand and supply networks to a common logistics network. The applied component offers students opportunities to apply the theoretical knowledge to specific applications, such as a "production planning control" problem for a retail garment supply chain in the textile industry. Other examples being developed are from the automotive and computer industries. This method of instruction facilitates comprehension by students of abstract system concepts in relation to real problems faced by industries. It also provides them exposure to development and/or use of the latest and relevant decision support software.

\section{CONCLUSIONS, EXTENSIONS, AND FUTURE WORK}

An overview of a web site for an instructional module on enterprise integration and supply chain management topics is offered. The design of the web site facilitates implementation of both learning and research components of the proposed web development framework. The dissemination of information from simple to complex topics pertaining to a research category satisfies audiences with discerning knowledge needs. The information presented in its current form on the web site is incomplete. Additional information for various research areas is still being collected, organized, and associated with various learning models. For this purpose, a better job of dissemination of information is required. In future, it is hoped to link live applications through the web site.

\section{REFERENCES}

1. Chandra, C., and S. Kumar, "Enterprise Systems: Challenges and Opportunities for Information Systems Education," Journal of Engineering Education, vol. 89, no. 1, January 2000, pp. 25-29.

2. Rettig, J., and C. LaGuardia, "Beyond 'Beyond Cool.' Reviewing Web Resources," Online vol. 23, Issue 4, July/August 1999, pp. 51-55.

3. Swack, T., "Case Studies in Strategy and User-Centered Design," Web Review, 1998, URL: http://webreview.com/wr/pub/web98east/18/ swackcase.ht.

4. Vassos, T., Strategic Internet Marketing, Macmillan Publishing Company Inc., 1996, p. 326.

5. Nielsen, J., "User Interface Directions for the Web," Communications of the ACM, vol. 42, no. 1, 1999, pp. 65-72.

6. Palmer, J.W., and D.A. Griffith, "An Emerging Model of Web Site Design for Marketing," Communications of the ACM, vol. 41, no. 3, March 1998, pp. 45-51.

7. Fielding, R.T., et al., "Web-Based Development of Complex Information Products," Communications of the ACM, vol. 41, no. 8, August 1998, pp. 84-92.

8. Miller, M.J., “Create a Great Site," PC Magazine, June 8, 1999, pp. $98-175$.

9. Chandra, C., "Enterprise Architectural Framework for Supply Chain Integration," Proceedings of the Sixth Annual Industrial Engineering Research Conference, May 17-18, 1997, Miami Beach, FL, pp. 873-878.

10. Chandra, C., "A Formal System Analysis Methodology for a Cooperative Supply Chain," Proceedings of the Second Annual International Conference on Industrial Engineering Applications and Practice, November 12-15, 1997, San Diego, CA. 